УДК 620.1:691.175.3

ББК 35.719

\title{
HIGH-STRENGTH REINFORCED PLASTICS
}

\author{
Kuperman Aleksandr Mikhaylovich \\ Candidate of Technical Sciences, Senior Researcher, Leading Researcher, \\ N. N. Semenov Institute of Chemical Physics, RAS \\ icp@chph.ras.ru \\ Kosygina St., 4, 119991 Moscow, Russian Federation
}

\section{Gorbatkina Yuliya Arkadyevna}

Doctor of Physical and Mathematical Sciences, Leading Researcher, Laboratory of Reinforced Plastics,

N. N. Semenov Institute of Chemical Physics, RAS

icp@chph.ras.ru

Kosygina St., 4, 119991 Moscow, Russian Federation

\section{Turusov Robert Alekseevich}

Doctor of Physical and Mathematical Sciences, Professor,

Department of General Physics,

Moscow Institute of Physics and Technology (MIPT)

fpfe@phystech.edu

Institutsky Pass., 9, 141700 Dolgoprudnyy, Russian Federation

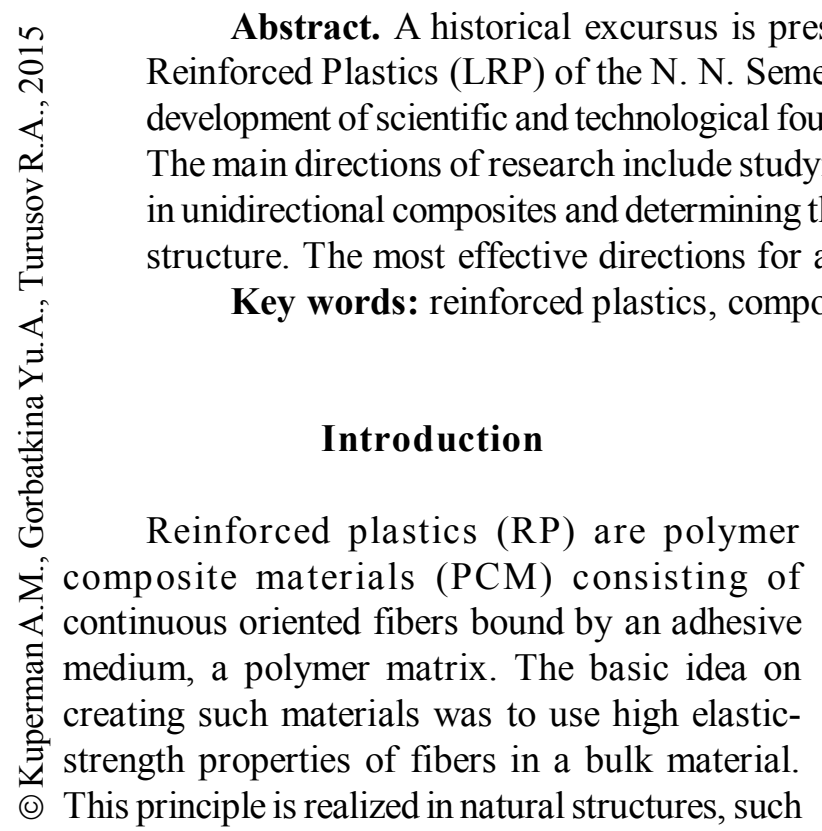

as plants and animal bones, which are anisotropic materials whose properties are adapted to the stresses that arise in specific directions.

Creation and development of RP in the 20th century was due to the appearance of continuous synthetic fibers with elastic-strength properties which are tens of times higher than those of natural fibers. First, this was glass fibers that were used as woven fillers in glass textolites. In the 
1940s, a prominent architect and scientist Andrey Konstantinovich Burov was apparently the first to formulate the principles of creating nonwoven oriented materials. He also proposed methods for producing glass-fiber anisotropic materials directly in the process of drawing fibers from the glass melting vessel $[1 ; 7 ; 8]$.

To implement his ideas and perform systematic research, in 1952 A.K. Burov established the Laboratory of Anisotropic Structures (LAS) at the Academy of Sciences, later on, the Laboratory of Reinforced Plastics within the Institute of Chemical Physics of the Academy of Sciences of the USSR. The task of the Laboratory consisted in the development of methods of production of such materials and investigation of their physicochemical and mechanical properties.

For many years, the laboratory was headed by Galina D. Andreevskaya, succeeded in 1984 by Eduard S. Zelenskii, both pupils and colleagues of A.K. Burov. At present Alexander M. Kuperman is the head of the Laboratory. Fig. 1 shows photographs of Laboratory Heads.

It should be noted that 60 years ago the scientific foundations for creation of synthetic anisotropic materials were practically absent, although the technology of these materials production and some application areas were already known. The rapid development of this industry has been associated with the creation of effective aircraft and rocket and space system needing in light and strong materials.

A turning point that gave rise to a new level of scientific and technological research was the emergence of carbon and organic (aramid) fibers, whose properties, especially specific, are substantially higher than those of glass-fibers [6;39].
The staff of the LRP was actively involved in solving new scientific and practical problems successfully cooperating with academic, educational and industrial organizations.

At different times the LRP's staff included six doctors and ten candidates of sciences. During this period eight monographs and hundreds of original papers in national and international journals have been published and more than 100 patents have been received.

\section{Main Directions of Research Performed at the Laboratory of Reinforced Plastics}

\section{Realization of the Strength of Fibers}

The approach developed by A.K. Burov to $\mathrm{RP}$ as a system of oriented fibers bound by a binder necessarily involves studying the realization of the elastic-strength properties of the fibers in the composite. Statistical micromechanical models proposed by Goulard and Rosen [7] suggest that the strength of the composite stretched along the fibers coincides with the strength of the bundle of unbound fibers over the so-called non-effective (critical) length $l_{\text {cr }}$, the value of which can be determined from the point of intersection of the scale dependences of the strength of the fibers and microplastics. The destruction of the material occurs via the accumulation of fiber ruptures. Such a hypothetical mechanism requires a large amount of energy and, accordingly, predicts a high strength of the composite. The respective tensile strength is given by the formula $\sigma_{f}^{t}=\left(\alpha \beta l_{\mathrm{cr}} e\right)^{-1 / \beta}$, where the $\alpha$ and $\beta$ are the Weibull distribution constants $[9 ; 30 ; 37]$.

In reality, because of the defects and nonuniform states of stress in the material, shear and
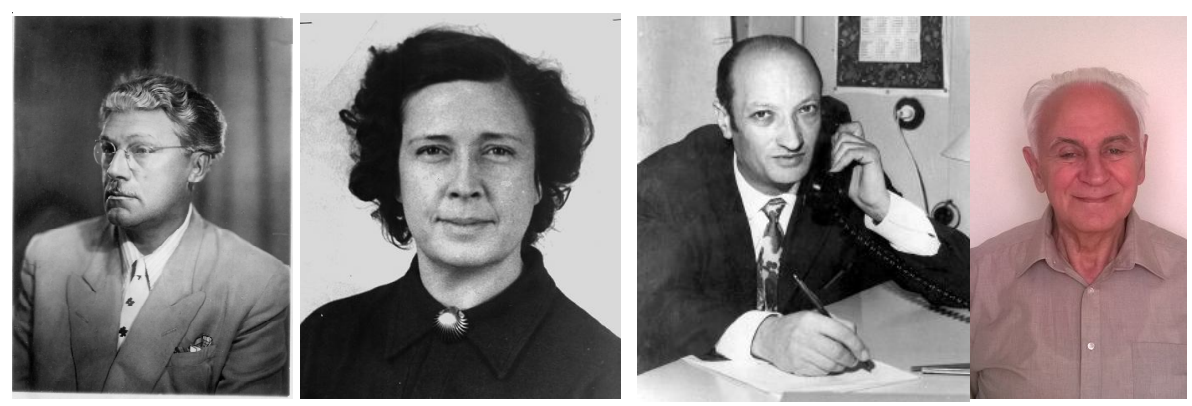

Fig. 1. Photographs of heads of the Laboratory of Reinforced Plastics: A.K. Burov, G.D. Andreevskaya, E.S. Zelenskii, and A.M. Kuperman 
transverse stresses arise which result in premature composite failure. The ratio of the tensile strength of the fibers in the composite $\sigma_{c}$ to the hypothetical tensile strength can be called the strength realization factor: $K=\sigma_{c} / \sigma_{f}^{t}$.

Measuring $l_{\mathrm{cr}}$ in the range of $0.1-1.0 \mathrm{~mm}$ is associated with difficulties in extrapolating the scale dependence of the strength of the fibers to the region of small lengths. Therefore, as a reference quantity, we can use the strength of a microplastic based on the primary fiber. We assume that the microplastic is destroyed by breaking the individual filaments as we observed slight dependence of microplastic strength on specimen lengths. For unidirectional ring-shaped specimens prepared from low-strength fibers, the strength realization factor is normally close to $100 \%$, being $70-80 \%$ for specimens based on high-strength fibers.

A similar approach can be used to assess the fiber strength realization factor for glass-fiber reinforced plastics under compression.In this case, the hypothetical strength, corresponding to fiber buckling stresses, calculated by the formula $\sigma_{f}^{t}=G_{m} / V_{m}$, where $G_{m}$ is the shear modulus of matrix material and $V_{m}$ is its volume fraction in the composite. The actual values of the strength realization factor lies within 50-80\%. The elastic modulus of fibers is usually realized fully in accordance with their volume fraction in the composite [9].

Dispersion of filaments lengths (multi-tensity of the filaments) in the threads and yarns arises at textile processing; the multi-tensity is a main factor aggravating non-uniform fibers destruction in real materials [3;9]. In cooperation with G.A. Aslanyan and S.L. Bazhenov our
Laboratory developed a mathematical model describing the process of filaments failure within the thread considering the dispersion of filaments lengths, the dispersion was estimated with the variation coefficient $v_{L}$. A method was proposed for experimental measurement of $u_{L}$ from the initial non-linear segment of the $\sigma-\varepsilon$ thread stress-strain curve. The plot in Fig. 2 shows an adequate agreement between theoretical and experimental results. The effect of multi-tensity of the filaments within a thread may be considered as an increase of the dispersion of individual filaments strength.

\section{Adhesion Strength in the Fiber-Polymer System}

Studying the adhesion strength $\tau_{\text {adh }}$ contributed significantly to studying the fracture mechanisms of composites.

The works of Yu.A. Gorbatkina and V.G. Ivanova-Mumzhieva won worldwide recognition $[5 ; 11]$. Dozens of organizations used the methods developed at the ICP RAS and adhesiometer of several types designed at the LAP. The pull-out method was employed to investigate how the strength of the fiber-matrix interface depends on the nature of fiber and binder, surface treatment of fiber, mode and degree of curing the polymer, the test temperature, loading rate, and modification of the matrix.

It is shown that the value of $\tau_{\text {adh }}$ depends on the shape and size of the interface and that the decrease in $\tau_{\text {adh }}$ with increasing length of the interface is mainly associated with the influence of residual (thermal) stresses as well as their distribution at the load process. Fig. 3 and 4 illustrate abovementioned ideas.

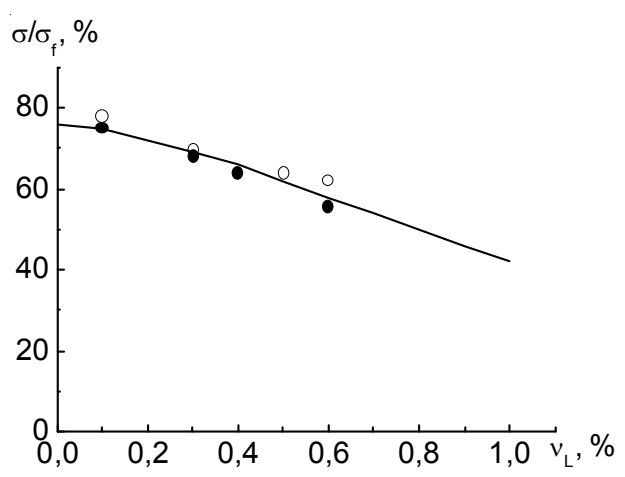

Fig. 2. Relative strength of a fiber bundle $\sigma / \sigma_{f}$ vs the variation coefficient of filament lengths $v_{L}$; the curve is the theoretical relationship for the bundle of free (unbound) organic filaments; experimental points are obtained in the tests of model thread specimens (o) and microplastics (•) 
As a measure of the adhesion strength and as a characteristic of the interacting pair, the local adhesion strength $\tau_{\text {loc }}$ was suggested, which is determined by extrapolating experimental data to a zero-length interface. It was found that the adhesion of epoxy binders to fibers with a high surface energy (steel, boron) is mainly associated with the formation of chemical bonds and that adhesive failure, like cohesive failure of the components, occurs by the thermal-fluctuation mechanism.

Studies of the adhesion of matrices modified with heat-resistant thermoplastics and disperse fillers (including nanosized) revealed the synergy of the interfacial strength when introducing 10 $20 \%$ of a modifier. The strength of unidirectional composites (glass, carbon, and organic reinforced plastics) was demonstrated to be related to the adhesion strength $\tau_{\text {adh }}$ for different types of stress states (tension, compression, bending, and shear).

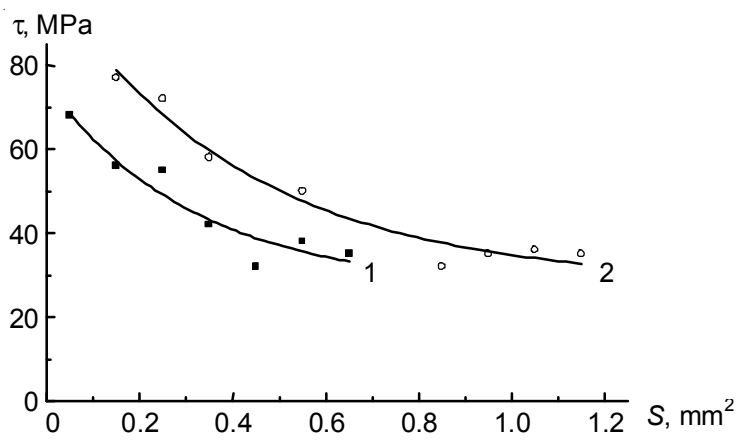

Fig. 3. Adhesive strength $\tau$ of polymer/steel wire joints as a function of the joint area $S$

Binders: 1 - polysulfone, 2 - ED-20 epoxy resin hardened with triethanolamine titanate; formation conditions: $1-300^{\circ} \mathrm{C}, 30 \mathrm{~min}$, and $2-180^{\circ} \mathrm{C}, 6 \mathrm{~h}$

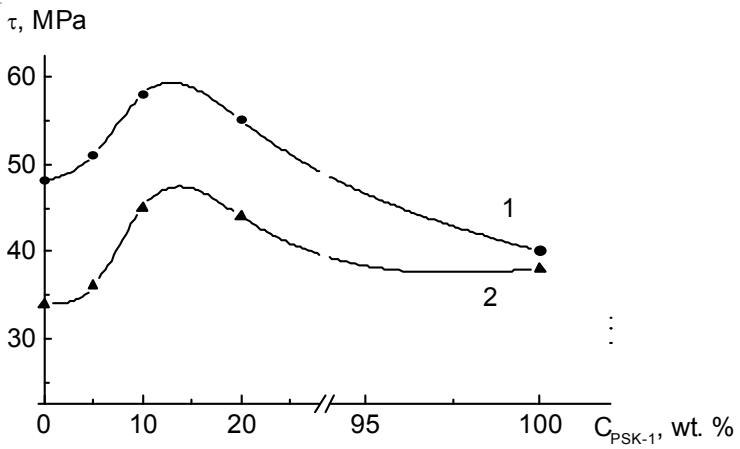

Fig. 4. Concentration dependences of the adhesive strength $\tau$ of joints between (ED-20 + TEAT + PSK-1) blends and steel wire $(d=150 \mu \mathrm{m})$

Cure conditions: $180{ }^{\circ} \mathrm{C}$ over $6 \mathrm{~h}$. Joint areas: $l-S=0.55 \mathrm{~mm}^{2}, l / d=7$, and $2-S=0.95 \mathrm{~mm}^{2}, l / d=13$
Studying the adhesion strength of a wide class of binders (epoxy, epoxy phenolic, phenol formaldehyde, organosilicon, polyester, and polyimide) made it possible to prepare reference data necessary for designing high-strength fiber composites on the basis of the known characteristics of the initial components.

A theory is proposed (named adhesion mechanics) which is based on the suggestion that a contact layer exists between the adhesive and substrate. The contact layer is a brush of short rods - the bonds. In terms of continuum this is the anisotropic layer. As a result, a theory was developed which enables one: (1) to calculate a significantly non-uniform stress and strain fields in adhesive joints including stress concentrations; (2) to meet all boundary conditions in contrast to rigorous solutions in line with the theory of elasticity when one obtains infinite values of tangential stresses (singularity) in corner points on load-free surfaces contrary to problem situation $[5 ; 35]$.

\section{Mechanics of Polymers and Composites}

Extensive studies aimed at elucidating the behavior of polymer matrix and composite materials under various loading conditions have been performed [5]. These studies were carried out under the guidance of an outstanding scientist A.L. Rabinovich. The results were interpreted within the framework of the generalized Maxwell-Gurevich equation, establishing a relationship between the strain $\varepsilon$ and stress $\sigma$ :

$$
\frac{d \mathrm{e}}{d t}=\frac{1}{E} \frac{d \mathrm{y}}{d t}+\frac{\left(\mathrm{y}-E_{\infty} \mathrm{e}^{*}\right)}{3^{*}} \exp \left|\frac{\left(\mathrm{y}-E_{\infty} \mathrm{e}^{*}\right)}{m^{*}}\right|,
$$

where $E_{\infty}$ is the high elasticity modulus, $\varepsilon^{*}$ is the highly elastic strain, $\eta *$ is the initial relaxation viscosity factor, and $m^{*}$ is the velocity modulus.

The constants of the equation were obtained under tension and compression in the following modes: constant strain rate $\left(V_{\varepsilon}=\right.$ const), elastic aftereffect $(\sigma=0)$, creep $(\sigma=$ const), and stress relaxation $(\varepsilon=$ const). A wide range of relaxation times was covered.

Equation was also used to describe deformation of glass-fiber reinforced plastics and to formulate the conditions of composite integrity: 
$E_{h} / E_{f} \geq 0.06, \phi_{\mathrm{adh}} \geq 0.015 \mathrm{y}_{f}, \mathrm{e}_{b} \geq 1.7 \mathrm{e}_{f}, \phi_{s} / \phi_{\mathrm{adh}} \geq 1$,

where $E_{b}$ and $\varepsilon_{b}$ are, respectively, the elasticity modulus and strain of the binder, whereas $E_{f}$ and $\varepsilon_{f}$ are the same parameters for the fibers.

The above relationships for the elasticstrength properties of the fibers and polymer matrix ensure the joint deformation of the components of polymer composite materials.

\section{PCM Developed at the Laboratory of Reinforced Plastics}

\section{Glass-fiber plastics (SVAM or GFAM) based on individual filaments}

The SVAM methods and materials were proposed by A.K. Burov. The methods for preparation of glass-fiber anisotropic materials (GFAM) involve application of binder onto the fibers and the formation of prepregs (or finished structural elements) in the process of drawing glass fibers with different diameters from the glass-melting vessel (Fig. 5, 6).

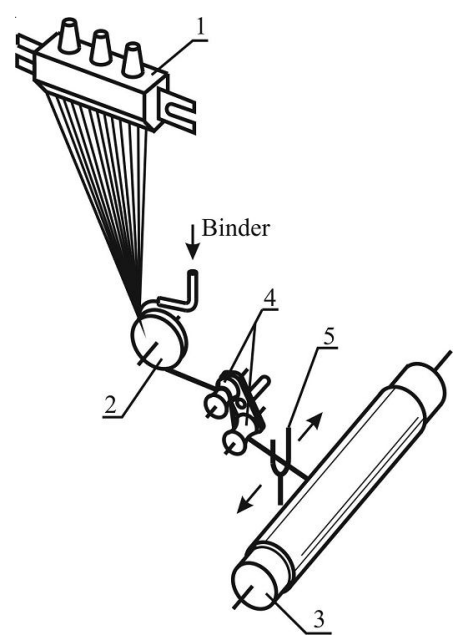

Fig. 5. Schematic of the installation for producing fiber-glass plastic items by winding individual fibers: 1 - glass-melting vessel; 2 - application roller; 3 - arbor; 4 - tension pulley; and 5 - placer

The speed of drawing of fibers ranged from a few meters per minute (for fibers with diameters of $50-150 \mu \mathrm{m})$ to a few meters per second (7-20 $\mu \mathrm{m}$ fibers). Accordingly, the conditions of impregnating the fibers with the binder, creating required tension, and forming the wound material varied. Proper technological methods, installation, and equipment for these processes have been developed: equipment for production of thin unidirectional and angle-plied veneer in sheets and bands produced by periodic and continuous methods. A method was also developed to wind radially strong elements: strengthened pipes, flywheels, generators, and other radially loaded items. Fig. 6 illustrates the main point of the method $[1 ; 7 ; 8 ; 14 ; 16]$.

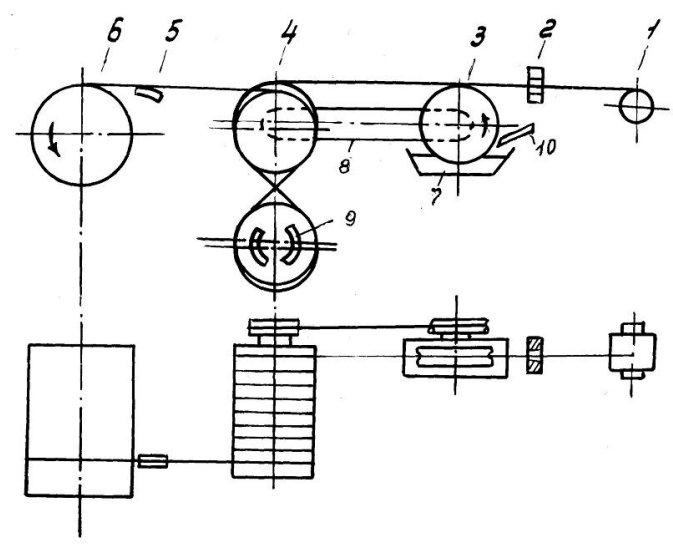

Fig. 6. Refined technological scheme of winding reinforced plastic items:

1 - bobbin; 2 - guiding orifice ring; 3 - application roller; 4 - impregnation-tension barrels; 5 - placer; 6 - arbor; 7 - binder bath; 8 - application roller drive; 9 - brake device; 10 - binder skimmer

GFAM materials have several features related to the production method. First of all, this is the maintenance of the initial strength of glass-fibers of various diameters from 5-7 to $100 \mu \mathrm{m}$. A confirmation is the multiple breaking of ring specimens under tension. The strength of such specimens significantly (by 20-30\%) increases the strength of analogous specimens based on ready-made threads. The absence of sizing agents gives higher atmosphere resistance, transparency of GFAM materials, higher (by an order) dielectric characteristics and the value of punch-through voltage. Finishing agents, specifically aminosilanes, are introduced into the binder $[14 ; 16]$.

Unfortunately these studies did not find proper industrial development because of their specificity. Nevertheless GFAM (SVAM) materials are well-known and have evident advantages as compared to any analogs.

\section{Glass-Fiber Reinforced Plastics Based on Ready-Made Threads and Yarns}

The first stage in impregnating the fibers with the binder significantly depends on wetting 
of the system which is commonly described by the height of capillary rise. We developed an original and statistically reliable method for determining the mentioned value [18].

For winding the structural elements from pre-prepared threads on the basis of glass, organic, carbon, or boron fibers, we developed a special impregnation-tension tract, which protects the fibers from damage and provides multiple impregnation of the material with the binder by means of pressure gradient $[10-12 ; 32]$. Considerable compaction of material structure is observed at the winding process. A schematic diagram of the tract is shown in Fig. 6.

Versions of the technological process allowing the use of binders with high viscosity have been developed. The fibers are impregnated with thermoplastics in the extruder head. As a result, a tape prepreg is produced, which is processed separately. One-step process can be realized by concurrently winding reinforcing fibers and matrix fibers $[26 ; 30 ; 38]$.

The winding of composites was usually carried out on an individual mandrel. As a result ring specimens were prepared, some of which were used to study the structural and physical and mechanical properties of the material. The content of the components and porosity were calculated on the basis of the thread/yarn linear density and technological parameters of winding. The tensile and compressive strengths of the specimen were determined using 72-cam devices or by tension the ring with half-disks. The modulus of elasticity of the ring was determined from the resonant frequency of oscillations, whereas cut ring segments were used to determine shear characteristics and specific fracture toughness (crack resistance) of the composite [27].

The study of material properties under tension showed that GRFP based on magnesiumaluminum-silicate "S" glass-fibers had elastic and strength properties $15-20 \%$ higher as compared to GFRP based on common aluminum-boronsilicate "E" glass-fibers. Applied epoxy binders considerably varied in mechanical properties, however this practically did not affect the properties of GRFP under tension. The highest properties were observed for ring specimens: $\sigma=2.5 \mathrm{GPa}, E=70 \mathrm{GPa}$. The properties of composites based on basalt and other mineral fibers were intermediate between the properties of "S" and "E" glass-fiber reinforced plastics.

It was shown that in order to increase compressive strength of GRFP, it was necessary to increase the fiber diameter up to 20 and more micrometers, increase the fiber volume fraction within the material and apply the binders with higher elastic and strength characteristics. On the basis of glass-fibers $20 \mathrm{\eta m}$ in diameter and a binder with high elastic and strength characteristics, we succeeded to create GFRP with high compressive strength of 2-3 GPa.

It was important to develop a test procedure to estimate reinforcing ability of GFRP under compression (analogous to the test procedure of microplastics under tension). Compression tests were performed in a closed mold which enabled us to obtain strict orientation of the fibers and thus prevent fibers buckling. Measured values of compressive strength of unidirectional GFRP tested with above mentioned mold were 1.2-1.5 times higher than maximum results obtained with the aid of 72cams device. In these cases we observed a change from shear failure mode to buckling failure mode of unidirectional GFRP under compression $[3 ; 14 ; 16]$.

In creating thick-walled fiberglass shells, we met the problem of their integrity due to a high probability of delamination of the shells under the influence of residual stresses arising from differences in the linear expansion coefficients of the components and constraints of binder shrinkage in anisotropic materials. Theoretical and experimental research made it possible to develop recommendations to overcome cracking of shells $[17 ; 20]$. Main of them are as follows:

- use of layer-by-layer fiber winding and curing of the shell;

- performance of a preliminary lowtemperature curing of the shell;

- creation of external compressive stresses by winding of thermocontractable layers.

\section{Aramid- and Carbon-Fiber Reinforced Plastics}

Aramid- and carbon-fiber reinforced plastics occupy a leading place among modern highstrength composites. They have a set of unique 
properties, notably a specific modulus of up to $10000 \mathrm{~km}$ and a specific strength of up to $350 \mathrm{~km}$. In the 1990s Russian and foreign scientists had achieved new remarkable successes. The strength of Armos-S and Rusar-S aramid fibers exceeded $6 \mathrm{GPa}$ at an elastic modulus of $180 \mathrm{GPa}$. A similar strength is characteristic of carbon fibers of Japanese (T-800) and American (IM-6 and AS-6) production, with an elastic modulus of $250 \mathrm{GPa}$ [6]. For example, Fig. 7 shows the distribution of the strength for 64 specimens of microplastics based on Rusar-S fiber.

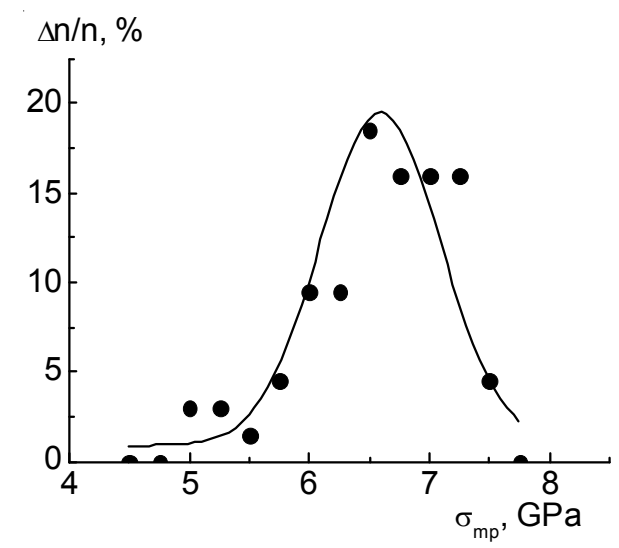

Fig. 7. Strength distribution for microplastics prepared from Rusar fibers

The mean value was found to be $6.7 \mathrm{GPa}$, with a variation coefficient of $3.7 \%$. The strength of three specimens exceeded 7.5 GPa. The elastic modulus was $160 \mathrm{GPa}$. Fig. 8 illustrates the strength of microplastics vs. the dispersion of their strength.

As it is evident from the data presented in Tables 1 and 2, the high strength of the individual aramid fibers are well realized in microplastics, with a fiber strength realization factor being $\sim 80 \%$ for ring specimens. Apparently, at high stresses, the binder cannot effectively prevent the development of defects. The deformability of the binder is often lower than that of the fiber. One should also take into account significantly different binder volume fraction in microplastics, $V_{\mathrm{mp}}$, and ring specimens, $V_{r}: V_{m p}=50 \%$ while $V_{r}=30 \%$. If one reduces the binder volume fraction in microplastics, the values of the fiber strength in microplastics and ring specimens commonly coincide.

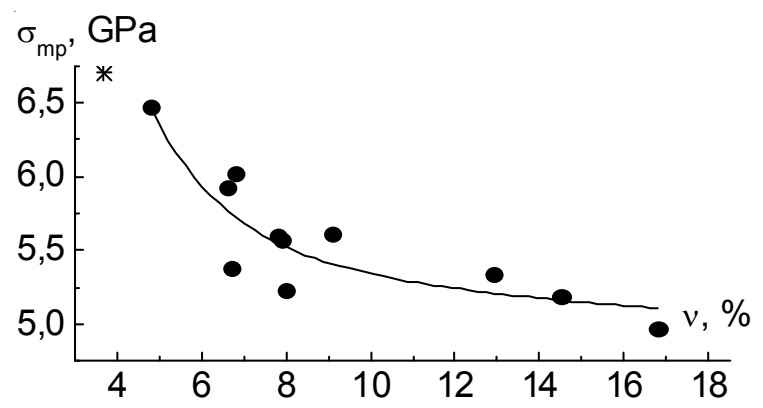

Fig. 8. Correlation between the strength of microplastic $\sigma_{m p}$ and its dispersion (coefficient of variation $\mathrm{U}$ ); $*$ is an additional result obtained in another test

Of interest is the fact that the strengths of organic plastics in tension and shear are practically independent of the type of binder. At the same time, the strength of carbon fiber increases when binders with high shear strength are used. This is probably due to a lower critical fiber length for carbon-fiber reinforced plastics.

The morphology of aramid fibers and the structure of filaments of Rusar, Armos, and Kevlar types have been studied. Images of their surface in the optical and electron microscopes at magnifications of $\times 25$ to $\times 100000$ were obtained. Figure 9 shows the structure of a filament at low $(\times 200, a)$ and high $(\times 50000, b)$ magnification.

Table 1

Tensile strength $\sigma$ (GPa) and elastic modulus $E$ (GPa) of aramid fiber and organic-fiber plastics (EDT-10 binder)

\begin{tabular}{|l|c|c|c|c|c|c|c|}
\hline & Individual fibers, & Microplastic, & \multicolumn{5}{|c|}{ Ring } \\
\cline { 4 - 8 } Fiber type & $\mathrm{y}_{f}$ & $\mathrm{y}_{m p}$ & $\mathrm{y}_{r}$ & $\mathrm{y}_{f}^{r}$ & $\mathrm{y}_{f}^{r} \mathrm{y}_{m p}$ & $\mathrm{E}_{r}$ & $\mathrm{E}_{f}^{r}$ \\
\hline SVM-4 & 4.4 & 4.3 & 2.4 & 3.9 & 0.90 & 72 & 115 \\
\hline Terlon & 4.1 & 2.8 & 1.8 & 2.4 & 0.88 & 97 & 135 \\
\hline Kevlar & 3.2 & 3.0 & 1.8 & 2.5 & 0.91 & 90 & 130 \\
\hline Rusar & - & 5.5 & 3.0 & 4.7 & 0.85 & 105 & 165 \\
\hline Armos & 5.1 & 4.9 & 2.8 & 4.5 & 0.92 & 98 & 159 \\
\hline
\end{tabular}


As can be seen from Fig. 9, $a$, the filaments consist of smooth uniform fibers without shape defects - only small fiber splicings and very small number of villi and scratches are observed. Along with surface defects, a magnification of $\times 5000$ makes it possible to resolve the linear structure oriented along the fiber axis. Fibrillar structure manifests itself in places with scratches on the fiber or near places of their cutting. Perhaps it reflects the internal fibrillar structure inherent to aramid fibers. At magnifications of $\times 50000 \ldots \times 100000$, details of delamination cracks are seen. In this case, a set of fibrils with a diameter of 50-200 $\mathrm{nm}$ is observable (Fig. 9, b). The fibrillar structure of Armos fibers is more pronounced, not near scratches but also within normal segment of the fiber surface. This is due to nonoptimal conditions of their production [20].

Heat resistance is one of the most important characteristics of PCM, which ensures operation in extreme conditions. The curves displayed in Fig. 10 show the temperature dependence of the strength of composites based on ordinary epoxy resins. These curves show a tendency to form a maximum, which can be attributed to an increase in the deformability of the binder during heating [9].

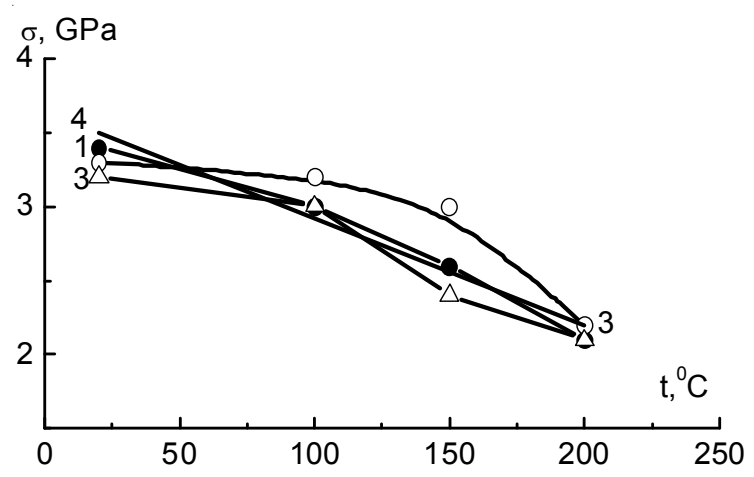

Fig. 10. Dependence of the strength of the fiber in annular specimens prepared from aramid fiber and (1) EDT-10, (2) EKhD-MK, and (3) EDF binders on the test temperature; curve 4 reflects the change of the strength of individual fibers

The class of heat-resistant polymers, which retain their performance characteristics at temperatures of $350-450{ }^{\circ} \mathrm{C}$ includes stiff-chain polybenzazole, polyimide, and polyoxazole matrices based on the ladder polymers (Fig. 11). It is worthwhile to mention IP-5 polymer, developed at the Institute Organoelement Chemistry of the Russian Academy of Sciences. Our studies performed in cooperation with the Federal State Unitary Enterprise "All-Russian Research Institute of Aviation Materials" demonstrated that the strength of carbon-

Table 2

\section{Tensile strength $\sigma$ (GPa) increase carbon-fiber reinforced plastics of various brands on the basis of EKT-15e and EDT-10}

\begin{tabular}{|c|c|c|c|c|c|c|c|c|c|c|}
\hline \multirow{2}{*}{ Binder } & AS-6 & IM-6 & T-800 & $\begin{array}{l}\text { UKN- } \\
5000 P\end{array}$ & \multicolumn{3}{|c|}{ UKN-5000P $*$} & \multicolumn{3}{|c|}{$\mathrm{T}-800 *$} \\
\hline & \multicolumn{4}{|c|}{$\mathrm{y}_{m p}$} & $\mathrm{y}_{t}$ & $\mathrm{y}_{c}$ & $\mathrm{y}_{s} \cdot 10^{2}$ & $\mathrm{y}_{t}$ & $\mathrm{y}_{c}$ & $\mathrm{y}_{s} \cdot 10^{2}$ \\
\hline EKT-15e & 5.11 & 5.16 & 5.61 & 2.86 & 1.72 & 1.04 & 8.5 & 3.07 & 2.56 & 7.0 \\
\hline EDT-10 & 3.92 & 3.93 & 5.26 & 2.23 & 1.34 & 0.76 & 6.4 & 2.74 & 2.27 & 5.7 \\
\hline
\end{tabular}

Notes. ${ }^{*}$-ring specimens.

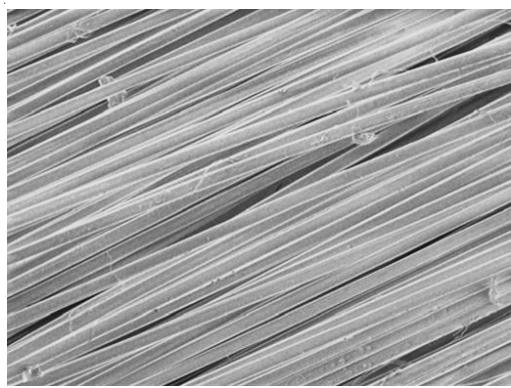

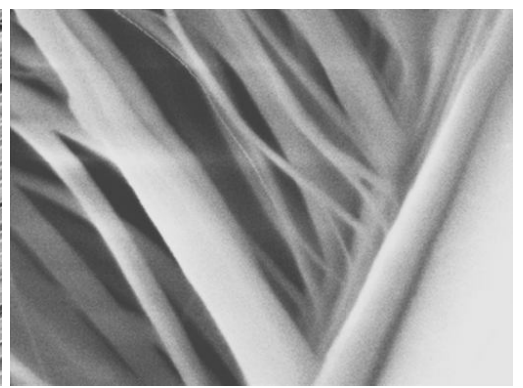

$b$

Fig. 9. Morphology of $(a)$ the surface of Armos aramid fibers (magnification $\times 200$ ) and $(b)$ fibrillar formations (magnification $\times 50000$ ) 


\section{ТЕХНИКО-ТЕХНОЛОГИЧЕСКИЕ ИННОВАЦИИ}

fiber reinforced plastic is preserved to a considerable extent $(50 \%)$ even at temperatures of $400-450{ }^{\circ} \mathrm{C}$. Heat-resistant organic-inorganic polymers were reported to be also very promising [17].

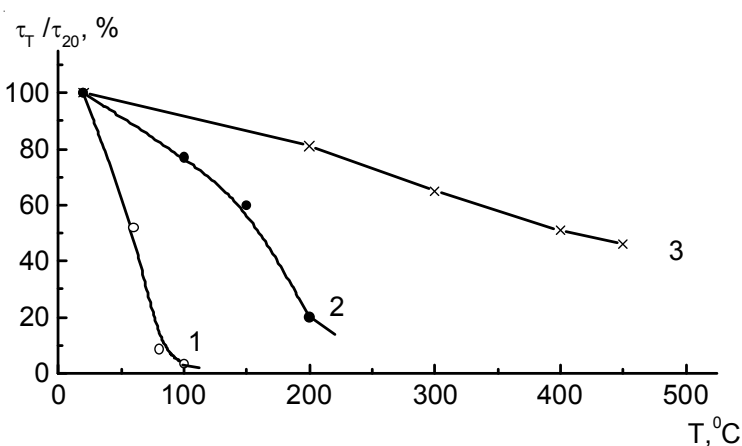

Fig. 11. Retention of the adhesive strength under test temperature variation for the joints of polymer - steel wire (150 $\mathrm{mm}$ in diameter $)$. Adhesive joint area $S=150 \mathrm{~mm}^{2}$

Polymers: 1 - epoxidiane binder EDT-10; 2 - polysulfone PSK-1; 3 - double-stranded polymer IP-5

\section{Glass- and Organic-fiber Reinforced Plastics with a High Fiber Fraction}

It was established that the elastic modulus and strength of RP increase proportionally to the content of fiber $V_{f}$. An important prerequisite for realizing this tendency is to preserve the porosity of the composite at a low level. Through the formation of the structure of wound item and through ultrasound exposure, the maximum possible value $V_{f}$ for fibers with a circular cross section was reached. Depending on the variance of the fiber diameter, it is $80-85$ volume \% (Fig. 12) [21].

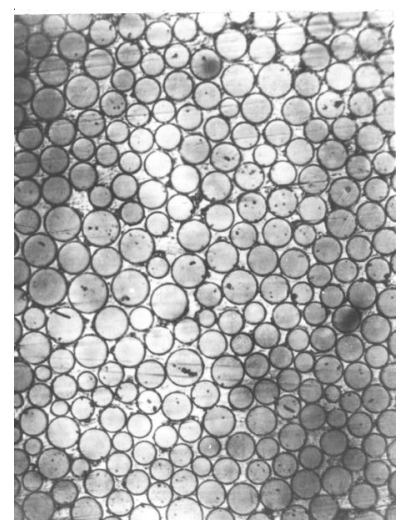

Fig. 12. Photograph of the microstructure of a fiber-glass plastic with a high content $(\sim 80 \%)$ of fiber
For aramid fibers PCM can be created with an extremely high $V_{f}, 90-95 \%$, which is achieved through the joint deformation of fibers at high temperatures with a change in the shape of their cross sections. We have developed two types of materials: highly reinforced organic-fiber plastics, in which the fibers are bound via thinnest polyepoxide layers, and ultimately reinforced organic-fiber plastics (Fig. 13), in which the integrity of the material is achieved through the autogenic interaction of fibers, so that the entire PCM can be thought of as single bulk fiber.

These materials have very high elasticstrength characteristics: an elastic modulus of $100 \mathrm{GPa}$ and a tensile strength of 2.5-3.2 GPa. At the same time, they are characterized by a low compressive and shear strength, which limits the use of these materials in structural elements, in which inhomogeneous stresses arise [13; 24].

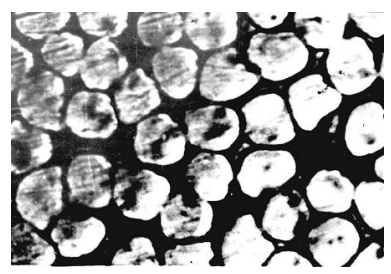

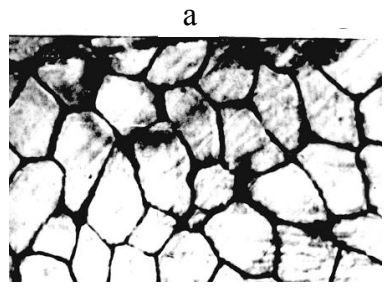

b

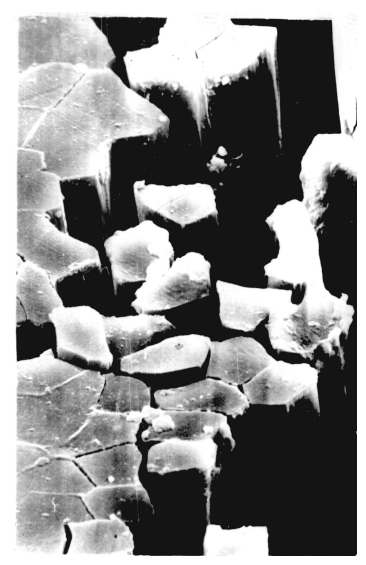

Fig. 13. Photographs of the microstructure of organic-fiber reinforced plastics:

$a$ - normally; $b$ - highly; $c$ - ultimately reinforced plastics

\section{Hybrid and Gradient PCM}

Creating hybrid and gradient composites (GPCM), containing two or more types of fibers, broadened the possibilities of creating materials with desired properties $[21 ; 24]$. The most important factor determining the mechanical behavior of GPCM is the ratio of the ultimate strains of the different reinforcing fibers. Those GPKM that contain fibers with a similar deformability are destroyed almost simultaneously, and the contribution of each component can be considered additive. Another character of the 
dependences is observed for GPKM containing fibers with different deformabilities. The ultimate strain of the composite is determined by the deformation of the fiber with higher volume fraction. Fig. 14 shows the stress-strain diagrams for glass-carbon-fiber reinforced plastics with various ratios of different-modulus fibers. In the first stage of loading (section I), fibers are deformed together. At $\varepsilon=0.7-1 \%$, specimens containing large amounts of carbon fibers fail first.

The final destruction of the carbon fibers in glass-fiber matrix occur within nonlinear section II, after which near-linear section III $(\varepsilon=1-2 \%)$ is observed, controlled by the elastic modulus and volume fraction glass-fiber, the destruction of which occurs at $\varepsilon=3-4 \%$. An increase in the strain of carbon fibers in the glass-fiber matrix is a synergistic effect caused by a multiple destruction of fibers and by the emergence of gaps between them. For repeated loading of the specimens, the $\sigma-\varepsilon$ dependences are linear, with an elastic modulus characteristic of the third section of the diagrams. For multiple (up to 10 cycles) loading of the specimen, no any changes in the diagrams were observed. Apparently, during repeated loadings, no additional carbon fiber fracture occurs. This result became the basis for developing effective strain gauges, which are made of carbon fiber destroyed in a fiberglass matrix [13].

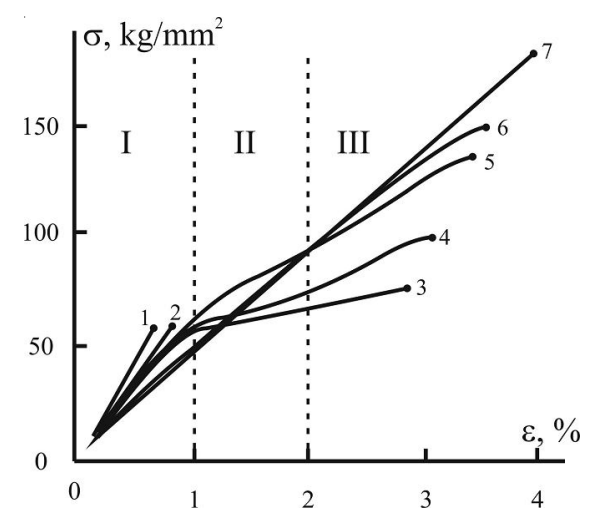

Fig. 14. The $\sigma-\varepsilon$ tension diagram for annular specimens of carbon-glass-fiber reinforced plastics at various fractions of glass-fiber:

$1-0,2-22,3-42,4-59,5-74,6-88$, and $7-100 \%$

A similar synergistic effect was observed during compression of GPCM. Carbon and organic fibers in glass or boron fiber reinforcing epoxy matrix can remain stable under strains and, hence, stresses 2 to 3 times larger than those admissible for carbon and organic fiber reinforced plastics. Here are examples of the most efficient combinations of fibers in different-modulus GPKM:

- combining glass and organic fibers makes it possible to prepare materials with high compressive and shear strength;

- a combination of glass and carbon fibers increases the elastic modulus of GPKM compared to fiberglass plastics [9].

For some structural elements (flywheels, thick-wall sheath), it is possible to select an optimal law of variation of the stiffness of the material over the cross section of the item. This is achieved by, for example, a combination of glass and carbon fibers in different ratios. Structures with nonuniform distribution of fibers are known as gradient structures. Almost all natural structures, such as stems, bones, needles, and beaks of animals are structures of this type.

\section{Reinforced Plastics Based on Hybrid Matrices that Combine Epoxy Binders with Additives of Thermoplastics and Dispersed Nanosized Particles}

Recent years have seen significant research on improving the properties of the binder, which should ensure the realization of the strength characteristics of fibers and meet the technological and operational requirements. Very promising is the use of hybrid matrices consisting of thermoplastics and thermosets. Investigation of epoxy binders modified with polysulfone showed a synergistic effect of increasing the adhesion strength of compositions containing polysulfone in an amount of 10-20\%. Significant increases in the fracture toughness and the strength of composites under low-speed impact loading was also observed (Table 3, Fig. 15). These effects are largely accounted by the complex structure of heterogeneous matrices [33].

Another direction of modification of epoxy matrices is the addition of fillers, such as Aerosil, carbon black, fullerenes, flakes of graphen oxide and carbon nanotubes, the dimensions of which are so small that they do not disturb the structure of the fiber composite.

It appeared to be very interesting to study elastic and strength properties of syntactics under 
shear; syntactics is epoxy binders filled with hollow glass microspheres. Several methods were compared for measuring syntactics properties, and the optimal methods were chosen. The study of the effect of volume components fractions gave us an idea on fracture mechanism of syntactics under compression and shear.

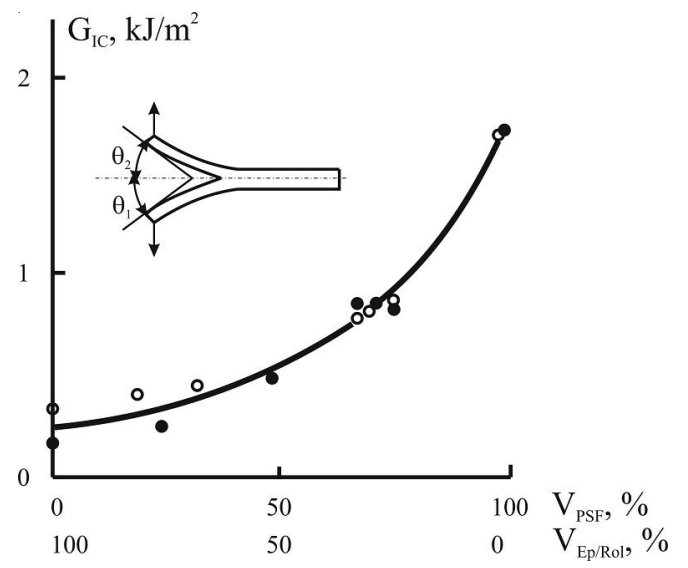

Fig. 15. Fracture toughness $G_{1 \mathrm{R}}$ as a function of the content of polysulfone in (o) epoxy and $(\bullet)$ rolivsan matrices. The value of $G_{1 \mathrm{R}}$ was calculated from the angles $\theta_{1}$ and $\theta_{2}$, as shown in the inset

For matrices modified with UM-66 carbon black particles, the concentration dependence of the bending strength of the composite features a maximum. The strength increases by $20 \%$ compared with that the respective unmodified composite. Fracture toughness $G_{1 \mathrm{R}}$ increases monotonically. The maximum increase in $G_{1 \mathrm{R}}$ constitutes $20 \%$ at a filler content of $5 \mathrm{wt} . \%$ of the binder.

Carbon nanotubes (CNTs) exhibit very high elastic-strength characteristics. As shown by theoretical and experimental studies, the elastic modulus of single-walled CNTs of diameter $10 \mathrm{~nm}$ is as high as $1000 \mathrm{GPa}$, with the tensile strength being $45 \mathrm{GPa}$.
To realize the properties of CNTs in reinforced plastics, it is very important to orient them in the polymer matrix along or perpendicular to the fibers, depending on the task at hand. In the first case, the elastic-strength properties of the composite are expected to improve, whereas in the second, the transverse and shear properties of the material are improved. In accordance with these views, we chose the method of orientation of CNTs [19].

First, we decided to add CNTs as a modifier to the polypropylene batch from which fibers were stretched. The orientation of CNTs along the fibers occurred mainly due to the subsequent deformation of the fibers. Fiber diameter decreased substantially, while the elastic modulus and strength of the specimens increased, respectively, to $E=5.5 \mathrm{GPa}$ and $\sigma=1.7-2.3 \mathrm{GPa}$. In this case, there was a twofold decrease in the relaxation characteristics of the filament, which is important for improving shape stability of the material.

In the second stage of research, we sought to orient CNTs perpendicular to the reinforcing fibers to increase the shear and transverse properties of composites without disturbing their general structure, so called 3D materials. To implement these intentions, an original method was used for the orientation of CNTs in a liquid polymer matrix by means of the induced dipole interaction of CNTs with a static or alternating electric field at electrophoresis regime. After reaching the required orientation of the CNTs, the binder was cured. To our knowledge, as applied to PCM, this method was used for the first time. The fact that the CNTs are oriented was confirmed by electron microscopy observation. We have proposed technological scheme for producing electric fields for conducting (carbon) and nonconducting (glass, organic) fibers for

Table 3

Shear strength $\tau_{s}$ (MPa) of fiber-glass plastics on the basis of an ED-22 epoxy matrix filled with Aerosil-380 or UM-66 carbon black at various loading rates

\begin{tabular}{|c|c|c|c|c|c|c|c|c|}
\hline \multirow{3}{*}{$V_{1}$} & \multicolumn{8}{|c|}{$C$, wt. $\%$} \\
\hline & 0 & 1 & 2,5 & 5 & 10 & 1 & 2,5 & 5 \\
\hline & \multicolumn{5}{|c|}{ Aerosil-380 } & \multicolumn{3}{|c|}{ UM-66 } \\
\hline $11 \mathrm{~mm} / \mathrm{min}$ & 65 & 51 & 51 & 56 & 56 & 60 & 61 & 58 \\
\hline $80 \mathrm{~mm} / \mathrm{min}$ & 65 & 60 & 59 & 62 & 60 & 62 & 60 & 59 \\
\hline $4 \mathrm{~m} / \mathrm{s}$ & 74 & 72 & 67 & 68 & 69 & 67 & 66 & 71 \\
\hline $5,4 \mathrm{~m} / \mathrm{s}$ & 80 & 72 & 69 & 73 & 67 & 65 & 67 & 72 \\
\hline
\end{tabular}


various conditions of orientation of CNTs. Model experiments have shown a doubling of the shear modulus of microplastics modified with CNTs, as well as the strength of annular specimens under shear (Fig. 16).

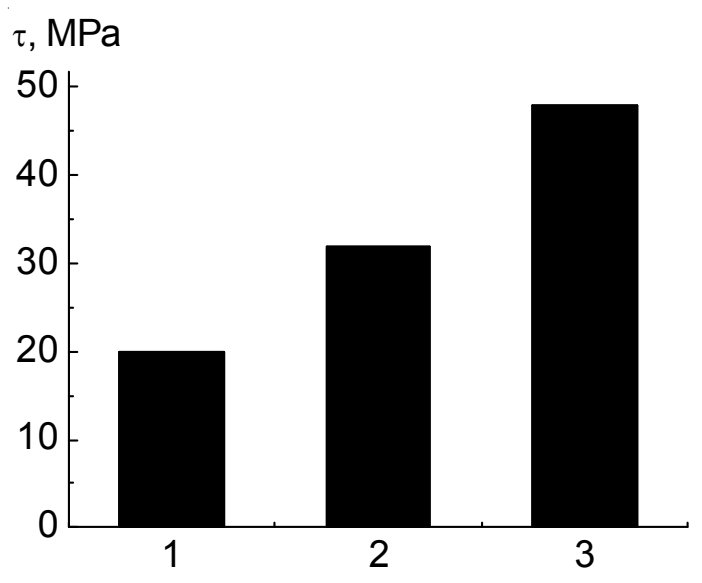

Fig. 16. Shear strength of fiberglass plastics on the basis of ED_20-E_181 epoxy binder modified with CNTs:

1 - reference specimens; 2 - random alignment of CNTs; 3 - oriented alignment of CNTs

\section{Conclusions}

Thus, the research we have conducted, in cooperation with academic, educational, and industry organizations, contributed significantly to the scientific and technological foundations of production of high-strength reinforced plastic. High-strength fibers and effective binders have been developed, and technological problems of impregnation and molding of RP by different methods have been solved. The most promising areas of their use were identified: missile and aerospace industry, transportation, armor, and sports equipment. At the same time, issues of further improving the properties of composites, primarily their performance characteristics are still very relevant.

\section{REFERENCES}

1. Andreevskaya G.D. High-Strength Oriented Glass-Fiber Reinforced Plastics. Moscow, Nauka Publ., 1966. (in Russian).

2. Baron A.A, Bakhracheva Yu.S. The Method for Lifetime Estimation Through the Mechanical
Properties in Tension. Mechanika (Kaunas), 2004, no. 3, pp. 29-32.

3. Bazhenov S.L., Kuperman A.M., Puchkov L.V., Zelenskiy E.S., Berlin A.A., Kharchenko E.F., Kulkov A.A. Statistical Aspects of Organic FiberReinforced Plastics Failure. Mechanics of Composite Materials, 1984, vol. 20, p. 706. (in Russian).

4. Bazhenov S.L., Kuperman A.M., Zelenskiy E.S., Berlin A.A. Compression Failure of Unidirectional Glass-Fibre Reinforced Plastics. Composite Science and Technology, 1992, vol. 4, pp. 201-208.

5. Berlin A.A., ed. Polymer Composite Materials: Structure, Properties, Engineering. Saint Petersburg, Professiya Publ., 2009.

6. Berlin A.A., Zelenskiy E.S., Kuperman M.A. Reinforced Plastics - From Chingiskhan Up to Now. Sum of Technologies, 2000, no. 2, p. 11. (in Russian).

7. Burov A.K., Andreevskaya G.D. Synthetic Fibrous Anisotropic Structure. Moscow, Publishing House of USSR Academy of Sciences, 1952. (in Russian).

8. Burov A.K. Author's Certificates no. 66818. 1941; 65025. 1945; 75081. 1946.

9. Chamis K. Micromechanics Strength Theories. Composite Materials. Vol. 5. Fracture and Fatigue. New York, Academic Press, 1975.

10. Denisov K.A., Kerber M.L. Kravchenko A.B., et al. The Features of Producing Tape Prepregs Based on Thermoplastic Matrices. Plastics, 1974, no. 4, p. 27. (in Russian).

11. Gorbatkina Ya.A. Adhesive Strength in Polymer-Fiber Systems. New-York-London, Ellis Horwood Ltd., 1992. 264 p.

12. Gorbatkina Ya.A., Ivanova-Mumzhieva V.G., Kuperman A.M., Ponomarev I.I. Sidorenko V.I. Adhesive Ability of Thermal Resistant DoubleStranded Polymer and Strength of Carbon-Fibre Reinforced Plastic Based on the Polymer. Mechanics of Composite Materials, 2008, vol. 44, no. 4, pp. 535545. (in Russian).

13. Kharchenko E.F. Structural Features of Organic Fibrous Materials Based on Profile Fibers. Chemical Fibers, 1986, no. 6, pp. 36-38. (in Russian).

14. Kuperman A.M., Bazhenov S.L., Aslanyan A.A., Berlin A.A., Zelenskiy E.S. On the Features of Failure of Glass-Fiber Reinforced Plastics Under Compression. The Reports of USSR Academy of Sciences, 1998, vol. 298, no. 6, pp. 1424-1427. (in Russian).

15. Kuperman A.M., et al. Impregnation-Tension Tract. Author's Certificate no. 249912, 1985.

16. Kuperman A.M., Gorbatkina Ya.A., Gorenberg A.Ya., Ivanova-Mumzhieva V.G. Physical and Mechanical Properties of the Fibers From Clinkers and the Material Based on These Fibers. Glass and Ceramics, 1988, no. 7, pp. 14-16. (in Russian). 


\section{ТЕХНИКО-ТЕХНОЛОГИЧЕСКИЕ ИННОВАЦИИ}

17. Kuperman A.M., Gorenberg Ya.A., Pavlovskiy D.V., Shamaev M.Yu., Oshmyan V.G., Zelenskiy E.S., et al. The Study of Technological Monolithity of Thick-Walled Glass-Fibre Reinforced Plastic Shells. Mechanics of Composite Materials and Structures, 2003, vol. 9, no. 1, pp. 65-86. (in Russian).

18. Kuperman A.M., Puchkov L.V., Zelenskiy E.S., et al. Proceedings of the International Conference on Mechanics and Technology of Composition Materials. Sofia, Nauka Publ., 1977, pp. 338-344. (in Russian).

19. Kuperman A.M., Zakharova T.Yu., Dubnikova I.L., Berlin A.A. Development of Methods for Carbon Nanotubes Orientation in a Polymer Medium. Chemical Engineer Encyclopedia, 2010, no. 9, pp. 9-12. (in Russian).

20. Kuperman A.M., Zelenskiy E.S. The Study of Technological Monolithity of Thick-Walled GlassFibre Reinforced Plastic Shells. Proceedings of the Novel Materials Held at Cavendish Laboratory. United Kingdom, Cambridge, 2001, p. 12.

21. Kuperman A.M., Zelenskiy E.S., Puchkov L.V. Investigating the Rules of Deformation of Hybrid Polymer Composite Materials. Proceedings of the 3rd International Conference on Mechanics and Technology of Composition Materials. Sofia, Nauka Publ., 1982, pp. 160-163.

22. Kuperman M.A. Methods for Producing High Strength Oriented Glass-Fiber Reinforced Plastics From Virgin Glass Filaments in the Process of Their Drawing From the Glass-Melting Vessel. Unrealized Potentials. Composites and Nanostructures, 2010, no. 1, p. 47. (in Russian).

23. Kuperman M.A., Zelenskiy E.S. The Method of Glass Reinforced Plastics Winding From Virgin Glass Monofilaments. Proceedings of the ICCM-10. Canada, Whistler Press, 1995, p. 477.

24. Molchanov Yu.M., Kuperman A.M., et al. Author's Certificate no. 132635, 1978.

25. Natrusov V.I., Roginskiy S.L., Gordon S.S., et al. Some Features of Winding Glass-Fiber Reinforced Plastics From Individual Glass Filaments of Large Diameter. Technology, Physicotechnical Properties and Application of Glass-Fiber Reinforced Plastics. Moscow, 1978, p. 92. (in Russian).

26. Pavlovskiy D.V., Golovkin G.S., Kuperman A.M., Zelenskiy E.S. A Method for Producing Products From Thermoplastic Composite Materials. RF Patent no. 2152306, 1998.

27. Puchkov L.V., Bazhenov S.L., Aslanyan A.A., Kuperman A.M., Gorbatkina Ya.A, Berlin A.A.,
Zelenskiy E.S. On the Mechanism of Glass-Fiber Reinforced Plastics Failure Under Compression. The Reports of USSR Academy of Sciences, 1985, vol. 284, no. 2, pp. 349-353. (in Russian).

28. Rabinovich A.L. Introduction Into Mechanics of Reinforced Polymers. Moscow, Nauka Publ., 1974.

29. Roginskiy S.L., Natrusov V.I. On the Effect of Glass-Fiber Diameter on Compressive Strength of Glass-Fiber Reinforced Plastics. Polymer Mechanics, 1972, no. 4, pp. 626-630. (in Russian).

30. Rosen B.V. Fibrous Composite Materials. Moscow, Mir Publ., 1967, pp. 54-97.

31. Semenova L.M., Bakhracheva Yu.S., Semenov S.V. Laws of Diffusion Layers Formation and Solution of the Diffusion Problem in TemperatureCycle Carbonitriding of Steel. Metal Science and Heat Treatment, 2013, vol. 55, no. 1-2, pp. 34-37.

32. Shapochkin V.I., Semenova L.M., Bakhra cheva Yu.S., Gyulikhandanov E.L., Semenov S.V. Effect of Nitrogen Content on the Structure and Properties of Nitrocarburized Sted. Metal Science and Heat Treatment, 2011, vol. 52, no. 9-10, pp. 413419.

33. Solodilov V.I., Korokhin R.A. Gorbatkina Ya.A., Kuperman A.M. Application of EpoxyPolysulfone Matrices for Winding Polymer Composite Materials. All Materials. Encyclopedic Handbook, 2009, no. 2, pp. 27-33. (in Russian).

34. Turusov R.A., Korotkov V.N., Rogozinskiy A.T., et al. Technological Monolithity of Polymer Composite Shells. Mechanics of Composite Materials, 1987, no. 6, pp. 1072-1076. (in Russian).

35. Turusov R.A., Manevich L.I. Introduction Into Adhesion Mechanics. Glues. Hermetics. Technologies, 2009, no. 5, pp. 2-8. (in Russian).

36. Turusov R.A., Manevich L.I. The Method of the Contact Layer in Adhesion Mechanics. Glues. Hermetics. Technologies, 2009, no. 6, pp. 2-11. (in Russian).

37. Weibull N.J. A Statistical Distribution Function of Wide Applicability. Applied Mechanics, 1951, vol. 18, pp. 293-297.

38. Zelenskiy E.S., Kulkov A.A., Kuperman M.A., et al. Technology of Wound Plastics. Journal of All-Russian Chemical Society, 1989, vol. 34, no. 5, pp. 515-552. (in Russian).

39. Zelenskiy E.S., Kuperman M.A., Gorbatkina Ya.A., Ivanova-Muzhmieva V.G., Berlin A.A. Reinforced Plastics. Modern Structural materials. Russian Chemistry Journal, 2001, vol. 45, no. 2, pp. 56-74. 


\section{ВЫСОКОПРОЧНЫЕ АРМИРОВАННЫЕ ПЛАСТИКИ}

\section{Куперман Александр Михайлович}

Кандидат технических наук,

старший научный сотрудник, ведущий научный сотрудник, Институт химической физики им. Н. Н. Семенова РАН icp@chph.ras.ru ул. Косыгина, 4, 119991 г. Москва, Российская Федерация

\section{Горбаткина Юлия Аркадьевна}

Доктор физико-математических наук, ведущий научный сотрудник лаборатории армированных пластиков, Институт химической физики им. Н. Н. Семенова РАН icp@chph.ras.ru ул. Косыгина, 4, 119991 г. Москва, Российская Федерация

\section{Турусов Роберт Алексеевич}

Доктор физико-математических наук, профессор кафедры общей физики, Московский физико-технический институт (МФТИ) fpfe@phystech.edu Институтский пер., 9, 141700 г. Долгопрудный, Российская Федерация

Аннотация. В обзоре представлена история лаборатории армированных пластиков Института химической физики РАН, которая внесла большой вклад в развитие научных и технологических основ получения и переработки этих материалов. Основные направления исследований включают изучение свойств волокон в однонаправленных композитах и определение ролей волокон, полимерной матрицы и структуры материала. В работе показаны наиболее эффективные направления применения этих материалов.

Ключевые слова: армированные пластики, композиты, полимерная матрица, структура материала, волокна. 